\title{
INVENTARISASI HAMA PADA PERLAKUAN DOSIS PUPUK KANDANG TERHADAP TANAMAN PADI KETAN PUTIH (Oryza sativa L. glutinosa)
}

\author{
Arif Setiyawan*, Sartono Joko Santosa, Kharis Triyono \\ Fakultas Pertanian, Universitas Slamet Riyadi, Surakarta \\ *E-mail: arifsetiyawan26041999@gmail.com
}

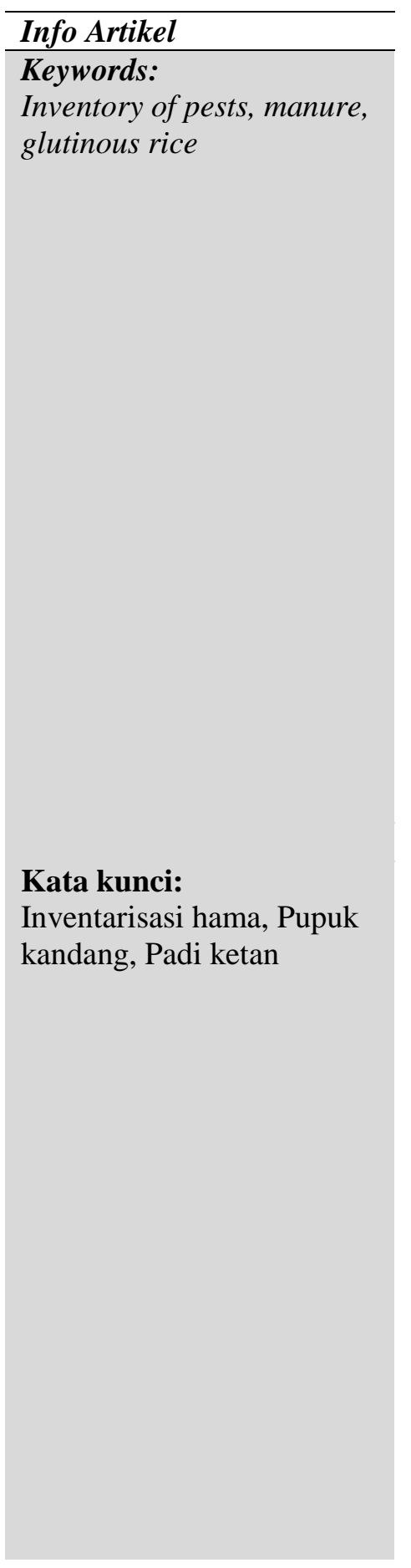

\begin{abstract}
The research on "The inventory of pests in the treatment of dosage manure for white glutinous rice crops (Oryza sativa L glutinosa)" was carried out from November 10th, 2019 until February 27th, 2020 in Donohudan village, Ngemplak District, Boyolali. This research aims to known the kinds of pests that attack white glutinous rice crops (Orzya sativa L glutinosa) as well as the degree of damage to the treatment of dosage manure. The research used a Random Complete Blok Design (RCBD) single factor consisting of 10 kinds treatments and repeated 3 times. The parameters observed are : kind of pests that attacked, the intensity of pest damage, the number of tillers per clump, weight of the dried grain harvest per plot, weight of 1000 grains. The results showed that (1) The types of pests that attack the treatment of manure doses of white glutinous rice plants (Oryza sativa $L$ glutinosa), namely locust pest, stem borer pests, and stinky bugs pest. (2) Treatment of manure goat dose $1.35 \mathrm{~kg} /$ plot (K3) is a dose of manure with the lowest level of pest attack on parameters the intensity of locust pest damage, stem borer pests, and stinky bugs pest. (3) The treatment of manure chicken has a significant effect on yields is the number of tillers per clump, the weight of the dried grain harvest per plot, and the weight of 1000 grains.
\end{abstract}

\section{Abstrak}

Penelitian tentang "Inventarisasi Hama Pada Perlakuan Dosis Pupuk Kandang Terhadap Tanaman Padi Ketan Putih (Oryza sativa L glutinosa)" telah dilaksanakan mulai tanggal 10 November 2019 sampai 27 Februari 2020 di Desa Donohudan, Kecamatan Ngemplak, kabupaten Boyolali. Penelitian ini bertujuan untuk mengetahui jenis - jenis hama yang menyerang tanaman padi ketan putih (Orzya sativa L glutinosa) serta tingkat kerusakan pada perlakuan dosis pupuk kandang. Penelitian menggunakan Rancangan Acak Kelompok Lengkap (RAKL) faktor tunggal yang terdiri dari 10 macam perlakuan dan diulang 3 kali. Parameter yang diamati meliputi : jenis hama yang menyerang, intensitas kerusakan hama, jumlah anakan per rumpun, berat gabah kering panen per petak, berat 1000 butir. Hasil penelitian menunjukkan bahwa (1) Jenis - jenis hama yang menyerang pada perlakuan dosis pupuk kandang terhadap tanaman padi ketan putih (Oryza sativa L glutinosa) yaitu hama belalang, hama penggerek batang, dan hama walang sangit. (2) Perlakuan pupuk kandang kambing dosis 1,35 kg/petak (K3) merupakan dosis pupuk kandang dengan tingkat serangan hama 
terendah pada parameter intensitas kerusakan hama belalang, hama penggerek batang, dan hama walang sangit.(3) Perlakuan pupuk kandang ayam berpengaruh nyata terhadap hasil panen yaitu jumlah anakan per rumpun, berat gabah kering panen per petak, dan berat 1000 butir.

\section{PENDAHULUAN}

Padi ketan putih (Oryza sativa L glutinosa) merupakan salah satu varietas padi golongan tanaman semusim. Tanaman ini mempunyai lidah tanaman dengan panjang 1-4 mm dan bercangkap dua. Helaian daun berbentuk garis dengan panjang $15-80 \mathrm{~cm}$, memiliki tepi kasar, memiliki malai dengan panjang 14-50 cm, dan akar yang menggantung (Maimunah, 2003).

Salah satu faktor yang perlu diperhatikan dalam pemeliharaan tanaman adalah pemupukan, sebab dengan pemupukan dapat memenuhi kebutuhan tanaman akan unsur hara yang diperlukan sehingga tanaman dapat tumbuh dengan baik. Demikian halnya pada penggunaan pupuk kandang sapi, ayam, dan kambing (Sigit, W., 2019)

Pupuk kandang dapat digunakan untuk mengendalikan nematoda, seperti pupuk kandang ayam, kambing, dan sapi. Senyawa kimia seperti nitrit, amoniak, hidrogen sulfida, dan asam-asam organik didalam pupuk kandang dapat membunuh nematoda di dalam tanah. Pupuk kandang dapat mempengaruhi lingkungan tanah sehingga meningkatkan populasi mikro organisme parasit telur nematoda (Schmitt, 1985).

Pupuk kandang juga mengandung unsur hara makro seperti N, P, K, dimana kandungan K yang cukup dapat menyebabkan tanaman lebih kuat dan tahan dari serangan hama dan penyakit. Hasil penelitian Hendrival, dkk (2014) menyatakan bahwa pupuk kalium dengan dosis $60 \mathrm{~g} / \mathrm{petak}$ dapat mengurangi populasi kutu daun Aphis glycines dan meningkatkan hasil kedelai dibandingkan dengan pemupukan kalium dosis $20 \mathrm{~g} /$ petak dan $40 \mathrm{~g} /$ petak.

Pemupukan kalium pada dosis $(70-100 \mathrm{~kg} / \mathrm{ha} / \mathrm{th})$ sudah cukup efektif untuk menekan perkembangan populasi tungau jingga (B. phoenicis) bila dibandingkan dengan dosis ( $40 \mathrm{~kg} / \mathrm{ha} / \mathrm{th})$ dan kontrol (Odih, 2014).

Tardapat kolerasi positif antara penambahan $\mathrm{N}$ dengan populasi dan tingkat serangan yang terjadi pada wereng hijau, wereng coklat, penggerek batang padi, dan tungau (Wasis, S. dan R. Heru,P., 2013)

Pertumbuhan dan produksi hasil tanaman dipengaruhi oleh berbagai faktor. Salah satu faktor yang dapat menyebabkan penurunan produktivitas dan hasil tanaman yaitu adanya serangan hama tanaman. Salah satu upaya preventif dalam mengurangi serangan hama adalah dengan budidaya tanaman sehat, dengan pengunaan pupuk yang tepat membuat tanaman sehat dan lebih tahan terhadap serangan hama. Akan tetapi pengunaan pupuk yang tidak tepat atau berlebih dapat menyebabkan tanaman keracunan dan rentan terhadap serangan hama.

Tujuan dari penelitian ini untuk mengetahui jenis-jenis hama yang menyerang tanaman padi ketan putih (Orzya sativa L Glutinosa) serta tingkat kerusakan pada perlakuan dosis pupuk kandang.

\section{BAHAN DAN METODE}

Penelitian ini menggunakan Rancangan Acak Kelompok Lengkap (RAKL) faktor tunggal yang terdiri dari 10 macam perlakuan dan diulang 3 kali, sehingga diperoleh 30 unit percobaan.

Penelitian ini dilaksanakan pada tanggal 10 november 2019 sampai 27 februari 2020 di Desa Donohudan, Kecamatan Ngemplak, Kabupaten Boyolali, dengan ketinggian tempat $\pm 150 \mathrm{mdpl}$ dengan jenis tanah Grumusol.

Bahan yang digunakan, antara lain : benih padi ketan putih varietas Ciasem, pupuk Urea, pupuk SP-36, pupuk KCL, pupuk kandang ayam, pupuk kandang kambing, pupuk kandang sapi. Pengamatan dilakukan pada 8 tanaman sampel setiap petaknya, dengan interval dua minggu sekali. Parameter 
pengamatan : jenis hama yang menyerang, intensitas kerusakan hama, jumlah anakan per rumpun, berat gabah kering panen per petak, berat 1000 butir.

\section{HASIL DAN PEMBAHASAN}

Tabel 1. Jenis Hama Yang Menyerang

\begin{tabular}{llc}
\hline \multicolumn{1}{c}{ Jenis Hama } & \multicolumn{1}{c}{ Nama Latin } & $\begin{array}{c}\text { Mulai serangan } \\
\text { Minggu Ke }\end{array}$ \\
\hline Belalang Hijau & Oxya chinensis & 5 \\
Penggerek Batang & Tryporyza innotata & 9 \\
Walang Sangit & Leptocorisa acuta & 11 \\
\hline Ketectangan &
\end{tabular}

Keterangan : Data awal muncul serangan hama dan awal pengamatan.

Hasil pengamatan yang dilakukan selama 13 minggu dengan interval 2 minggu sekali menunjukkan jenis hama yang menyerang tanaman padi ketan putih yaitu belalang, penggerek batang, dan walang sangit. Hama ini menyerang pada setiap perlakuan dosis pupuk kandang dengan intensitas kerusakan dan waktu yang berbeda-beda.

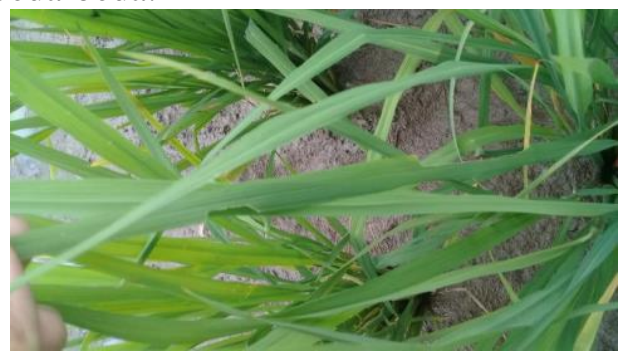

(a) Gejala serangan belalang

Serangan hama belalang mulai terjadi pada minggu ke 5. Hama belalang merupakan hama yang dapat ditemui pada fase vegetatif sampai fase generatif. Hama belalang menyerang tanaman padi dengan cara memakan tepi daun yang mengakibatkan daun menjadi rusak dan berlubang. Gejala yang ditimbulkan akibat dari serangan hama belalang yaitu daun berlubang dengan tepi bergerigi dan kasar. Kerusakan yang ditimbulkan hama belalang pada skala besar cukup memprihatinkan karena dapat mengurangi produktifitas tanaman padi yang terserang.

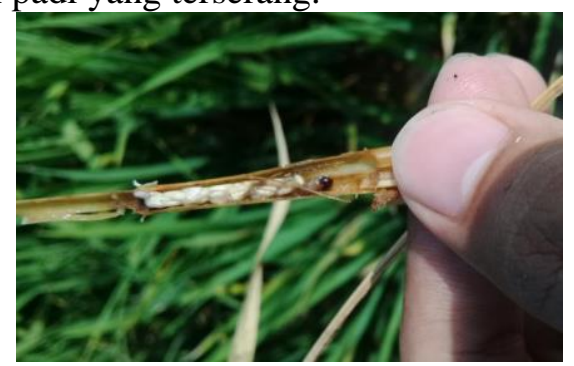

(b) Gejala serangan penggerek batang

Hama penggerek batang muncul dan menyerang pada minggu ke 9. Hama penggerek batang menyerang pada titik tumbuh tanaman padi yang dimakan oleh larva penggerek batang. Penggerek batang padi dapat menyerang tanaman padi mulai dari pembibitan hingga fase produktif. Gejala serangan yang ditimbulkan akibat serangan penggerek batang yaitu daun menguning dan mengering diawali dari ujung daun hingga batang serta tanaman padi mudah dicabut. Serangan penggerek batang pada fase vegetatif disebut "sundep" sedangkan serangan terjadi pada fase generatif disebut "beluk". 
ISSN (Print) : 1693-0738

ISSN (Online) : 2714-5549

Innofarm:Jurnal Inovasi Pertanian Vol. 22 (1), April 2020

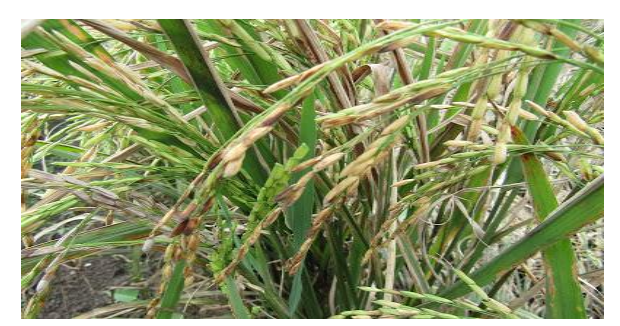

(c) Gejala serangan walang sangit

Hama walang sangit muncul dan menyerang tanaman padi ketan putih pada minggu ke 11. Hama walang sangit menyerang tanaman padi mulai bulir padi keluar sampai fase pematangan, serangan terberat pada fase matang susu. Walang sangit menyerang tanaman padi dengan cara menusukkan dan menghisab cairan yang ada pada bulir padi sehingga menyebabkan bulir padi hampa, atau bulir padi menjadi kecil, ciri khusus dari serangan hama walang sangit yaitu terdapat titik hitam pada bulir padi bekas tusukan.

Tabel 2. Intensitas Kerusakan hama

\begin{tabular}{cccc}
\hline \multirow{2}{*}{ Perlakuan } & \multicolumn{3}{c}{ Macam Hama } \\
\cline { 2 - 4 } & Belalang & Penggerek Batang & Walang Sangit \\
\hline D0 & $15,41 \mathrm{a}$ & $27,20 \mathrm{a}$ & $37,33 \mathrm{~b}$ \\
A1 & $19,60 \mathrm{bc}$ & $35,69 \mathrm{a}$ & $37,67 \mathrm{~b}$ \\
A2 & $21,39 \mathrm{~cd}$ & $37,03 \mathrm{a}$ & $39,00 \mathrm{~b}$ \\
A3 & $22,65 \mathrm{~d}$ & $37,75 \mathrm{a}$ & $39,33 \mathrm{bc}$ \\
K1 & $14,21 \mathrm{a}$ & $25,66 \mathrm{a}$ & $35,00 \mathrm{ab}$ \\
K2 & $14,85 \mathrm{a}$ & $21,15 \mathrm{a}$ & $35,33 \mathrm{~b}$ \\
K3 & $13,13 \mathrm{a}$ & $16,71 \mathrm{a}$ & $31,33 \mathrm{a}$ \\
S1 & $13,60 \mathrm{a}$ & $26,82 \mathrm{a}$ & $41,00 \mathrm{~cd}$ \\
S2 & $15,27 \mathrm{a}$ & $22,40 \mathrm{a}$ & $38,33 \mathrm{~b}$ \\
S3 & $16,16 \mathrm{ab}$ & $19,70 \mathrm{a}$ & $43,00 \mathrm{~d}$ \\
\hline
\end{tabular}

Keterangan : Purata intensitas kerusakan hama yang diikuti huruf sama berarti tidak berbeda nyata pada taraf $5 \%$ uji BNJ.

Tabel 2 menunjukkan bahwa perlakuan pupuk kandang ayam dosis 4,5 kg/petak (A3) menghasilkan intensitas kerusakan hama belalang tertinggi yaitu 22,65 dan berpengaruh nyata terhadap perlakuan pupuk kandang kambing dosis $0,45 \mathrm{~kg} /$ petak (K1), pupuk kandang kambing dosis $0,9 \mathrm{~kg} /$ petak (K2), pupuk kandang kambing dosis $1,35 \mathrm{~kg} /$ petak (K3), pupuk kandang sapi dosis 1,5 $\mathrm{kg} /$ petak (S1), pupuk kandang sapi dosis 3,0 kg/petak (S2), pupuk kandang sapi dosis 4,5 kg/petak (S3), pupuk kandang ayam dosis 1,5 kg/petak (A1), dan tanpa perlakuan dosis pupuk kandang (D0), akan tetapi tidak berbeda nyata terhadap perlakuan pupuk kandang ayam dosis 3,0 kg/petak (A2). Serangan hama belalang tertinggi pada perlakuan pupuk kandang ayam akan tetapi hasil jumlah anakan tertinggi juga terdapat pada perlakuan pupuk kandang ayam. Hama belalang memiliki ketertarikan terhadap bau-bau yang menyengat seperti bau bangkai dan bau telur busuk. Pupuk kandang ayam memiliki bau yang menyengat dan tidak sedap, hal ini yang diduga menyebabkan serangan hama belalang lebih tinggi pada perlakuan pupuk kandang ayam meskipun hasil jumlah anakan tertinggi. Selain itu dengan kandungan $\mathrm{N}$ yang semakin tinggi ini menyebabkan tanaman padi lebih subur dan lebat sehingga sumber pakan bagi belalang lebih banyak.Perlakuan pupuk kandang kambing dosis 1,35 kg/petak (K3) menghasilkan intensitas kerusakan hama belalang terendah yaitu 13,13, Berdasarkan hasil analisi kimia pupuk kandang bahwa pupuk kandang kambing mengandung $\mathrm{K}$ total lebih tinggi yaitu 1,70\% dibandingkan dengan pupuk kandang ayam dan sapi, dengan kandungan $\mathrm{K}$ yang tinggi menyebabkan jaringan 
batang, daun tanaman lebih kuat serta kinerja enzim dalam tanaman lebih optimal sehingga tanaman lebih tahan dari serangan hama belalang.

Perlakuan pupuk kandang ayam dosis 4,5 kg/petak (A3) menghasilkan intensitas kerusakan hama penggerek batang tertinggi yaitu 37,75 akan tetapi tidak berbeda nyata terhadap perlakuan lain. Hal ini karena penyebaran hama penggerek batang terjadi dilakukan oleh imago penggerek batang yang meletakkan telurnya pada batang tanaman padi, imago penggerek batang meletakkan telurnya secara acak pada tanaman asalkan tanaman tersebut merupakan tanaman inang. Sedangkan serangan penggerek batang dilakukan oleh larva penggerek batang yang tadinya merupakan telur dari penggerek batang, hal ini yang menyebabkan serangan hama penggerek batang tiap petak perlakuan bahkan antar ulangan berbeda-beda tergantung imago penggerek batang meletakkan telurnya. Serangan hama penggerek batang tertinggi pada perlakuan pupuk kandang ayam dan hasil jumlah anakan tertinggi pada perlakuan pupuk kandang ayam diduga dengan hasil jumlah anakan tertinggi mengakibatkan kondisi lingkungan disekitar lebih lembab sehingga struktur batang lebih lunak, ini yang menyebabkan larva penggerek batang lebih mudah untuk masuk kedalam batang tanaman padi dan menggerek titik timbuh tanaman padi.

Perlakuan pupuk kandang sapi dosis 4,5 kg/petak (S3) menghasilkan intensitas kerusakan hama walang sangit tertinggi yaitu 43,00 akan tetapi tidak berbeda nyata terhadap perlakuan pupuk kandang sapi dosis 1,5 kg/petak (S1) dengan rata-rata 41,00, sedangkan berbeda nyata terhadap perlakuan pupuk kandang ayam dosis 1,5 kg/petak (A1), pupuk kandang ayam dosis $3 \mathrm{~kg} /$ petak (A2), pupuk kandang ayam dosis 4,5kg/petak (A3), pupuk kandang kambing dosis 0,45 kg/petak (K1), pupuk kandang kambing dosis 0,9 kg/petak (K2), pupuk kandang kambing dosis 1,35 kg/petak (K3), pupuk kandang sapi dosis $3 \mathrm{~kg} /$ petak (S2), dan tanpa dosis pupuk kandang (D0). Sesuai dengan hasil analisis kimia pupuk kandang menunjukkan pupuk kandang sapi memiliki kandungan $\mathrm{K}$ total paling rendah yaitu $1,02 \%$, hal ini yang diduga menyebabkan serangan hama walang sangit cukup tinggi. Sedangkan pada perlakuan pupuk kandang kambing dosis $1,35 \mathrm{~kg} /$ petak menghasilkan intensitas kerusakan hama walang sangit terrendah yaitu 31,33 akan tetapi tidak berbeda nyata terhadap perlakuan pupuk kandang kambing dosis $0,45 \mathrm{~kg} /$ petak dengan intensitas kerusakan hama yaitu 35,00. Tabel 3. Hasil Panen

\begin{tabular}{cccc}
\hline \multirow{2}{*}{ Perlakuan } & \multicolumn{3}{c}{ Hasil Panen } \\
\cline { 2 - 4 } & $\begin{array}{c}\text { Jumlah anakan } \\
\text { per rumpun }\end{array}$ & $\begin{array}{c}\text { Berat gabah kering } \\
\text { panen per petak (Gram) }\end{array}$ & $\begin{array}{c}\text { Berat } 1000 \text { butir } \\
(\text { Gram })\end{array}$ \\
\hline D0 & $23 \mathrm{ab}$ & $1115,58 \mathrm{a}$ & $31,40 \mathrm{a}$ \\
$\mathrm{A} 1$ & $27 \mathrm{abc}$ & $1420,87 \mathrm{ab}$ & $36,57 \mathrm{ab}$ \\
$\mathrm{A} 2$ & $31 \mathrm{bc}$ & $1536,50 \mathrm{ab}$ & $36,67 \mathrm{ab}$ \\
$\mathrm{A} 3$ & $32 \mathrm{c}$ & $1820,90 \mathrm{~b}$ & $34,60 \mathrm{ab}$ \\
$\mathrm{K} 1$ & $19 \mathrm{a}$ & $1356,08 \mathrm{ab}$ & $36,57 \mathrm{ab}$ \\
$\mathrm{K} 2$ & $22 \mathrm{a}$ & $1372,54 \mathrm{ab}$ & $36,53 \mathrm{ab}$ \\
K3 & $21 \mathrm{a}$ & $1476,56 \mathrm{ab}$ & $36,87 \mathrm{~b}$ \\
S1 & $20 \mathrm{a}$ & $1328,62 \mathrm{ab}$ & $36,83 \mathrm{~b}$ \\
S2 & $21 \mathrm{a}$ & $1345,93 \mathrm{ab}$ & $33,73 \mathrm{ab}$ \\
S3 & $23 \mathrm{a}$ & $1432,44 \mathrm{ab}$ & $35,97 \mathrm{ab}$ \\
\hline
\end{tabular}

Keterangan : Purata hasil panen yang diikuti huruf sama berarti tidak berbeda nyata pada taraf 5\% uji BNJ.

Perlakuan pupuk kandang ayam dosis 4,5 kg/petak (A3) menghasilkan jumlah anakan per rumpun tertinggi yaitu 32 dan berbeda nyata terhadap perlakuan tanpa dosis pupuk kandang (D0), pupuk kandang kambing dosis 0,45 kg/petak (K1),pupuk kandang kambing dosis 0,9 kg/petak (K2), pupuk kandang kambing dosis 1,35 kg/petak (K3), pupuk kandang sapi dosis 1,5 kg/petak (S1), pupuk kandang sapi dosis $3 \mathrm{~kg} /$ petak (S2), pupuk kandang sapi dosis 4,5 kg/petak (S3), akan tetapi tidak 
berberbeda nyata terhadap perlakuan pupuk kandang ayam dosis 3,0 kg/petak (A2) yaitu 31 dan pupuk kandang ayam dosis $1,5 \mathrm{~kg} /$ petak (A1) yaitu 27 . Sesuai dengan hasil analisis pupuk kandang bahwa kandungan $\mathrm{N}$ total pada pupuk kandang ayam jauh lebih tinggi dibandingkan dengan pupuk kandang sapi dan kambing. Seperti yang diketahui bahwa salah satu manfaat unsur hara $\mathrm{N}$ bagi tanaman adalah untuk memacu pertumbuhan vegetatif seperti tinggi tanaman, jumlah cabang, dan jumlah anakan.

Perlakuan pupuk kandang ayam dosis 4,5 kg/petak (A3) menghasilkan berat gabah kering panen tertinggi yaitu 1820,90 gram, dan berbeda nyata terhadap perlakuan tanpa pupuk kandang (D0), tetapi tidak berbeda nyata terhadap perlakuan pupuk kandang ayam dosis $1,5 \mathrm{~kg} /$ petak (A1), pupuk kandang ayam dosis 3,0 kg/petak (A2), pupuk kandang kambing dosis 0,45 kg/petak (K1), pupuk kandang kambing dosis 0,9 kg/petak (K2), pupuk kandang kambing dosis 1,35 kg/petak (K3), pupuk kandang sapi dosis 1,5 kg/petak (S1), pupuk kandang sapi dosis 3,0 kg/petak (S2), pupuk kandang sapi dosis 4,5 kg/petak (S3). Kandungan $\mathrm{N}$ yang tinggi mengakibatkan pertumbuhan fegetatif seperti tinggi tanaman dan jumlah anakan semakin meningkat sehingga jumlah anakan produktif yang dihasilkan juga ikut meningkat, hal ini yang diduga menyebabkan hasil berat gabah kering panen per petak lebih tinggi dibandingkan dengan pupuk kandang lain.

Perlakuan pupuk kandang kambing dosis $1,35 \mathrm{~kg} /$ petak (K3) menghasilkan berat 1000 butir tertinggi yaitu 36,87 gram, dan berbeda nyata terhadap perlakuan tanpa dosis pupuk kandang (D0), tetapi tidak berbeda nyata terhadap perlakuan pupuk kandang ayam dosis 1,5 kg/petak (A1), pupuk kandang ayam dosis 3,0 kg/petak (A2), pupuk kandang ayam dosis 4,5 kg/petak (A3), pupuk kandang kambing dosis 0,45 kg/petak (K1), pupuk kandang kambing dosis 0,9 kg/petak (K2), pupuk kandang sapi dosis 1,5 kg/petak (S1), pupuk kandang sapi dosis 3,0 kg/petak (S2), dan pupuk kandang sapi dosis 4,5 kg/petak (S3). Berdasarkan hasil pengamatan intensitas kerusakan hama walang sangit serangan terrendah pada perlakuan pupuk kambing dosis $1,35 \mathrm{~kg} /$ petak $(\mathrm{K} 3)$, diduga dengan serangan walang sangit yang rendah mengakibatkan pengisian bulir padi pada perlakuan pupuk kandang kambing dosis $1,35 \mathrm{~kg} /$ petak lebih optimal karena cairan pada bulir padi tidak hilang sehingga menghasilkan bulir padi yang lebih besar dan berisi. Perlakuan tanpa pemberian pupuk kandang (D0) menghasilkan berat 1000 butir terrendah yaitu 31,40 gram. Perlakuan (D0) merupakan perlakuan tanpa diberi pupuk kandang sehingga diduga kekurangan unsur hara, hal ini yang menyebabkan pengisian bulir padi tidak optimal sehingga mengakibatkan bulir padi yang dihasilkan lebih kecil dibandingkan dengan perlakuan lain.

\section{KESIMPULAN}

1. Jenis - jenis hama yang menyerang pada perlakuan dosis pupuk kandang terhadap tanaman padi ketan putih (Oryza sativa L glutinosa) yaitu hama belalang dengan awal serangan umur 5 MST (Minggu Setelah Tanam) dengan intensitas kerusakan terrendah pada perlakuan pupuk kandang kambing dosis 1,35 kg/petak (K3) yaitu 13,13. Hama walang sangit dengan awal serangan 11 MST (Minggu Setelah Tanam) dengan intensitas kerusakan hama terrendah pada perlakuan pupuk kandang kambing dosis 1,35 kg/petak yaitu 34,02, tetapi perlakuan dosis pupuk kandang tidak berpengaruh nyata terhadap hama penggerek batang dengan awal serangan 9 MST (Minggu Setelah Tanam).

2. Perlakuan pupuk kandang kambing dosis $1,35 \mathrm{~kg} /$ petak (K3) pada tanaman padi ketan putih (Oryza sativa L glutinosa) dapat menekan intensitas kerusakan hama belalang, hama penggerek batang, dan hama walang sangit.

3. Perlakuan pupuk kandang ayam dosis $4,5 \mathrm{~kg} /$ petak (A3) berpengaruh nyata terhadap hasil panen pada jumlah anakan per rumpun yaitu 32 anakan, berat gabah kering panen per petak yaitu 1820,90 gram, dan berat 1000 butir yaitu 36,87 gram.

\section{DAFTAR PUSTAKA}

Hendrival, Latifah, dan Idawati. 2014. Pengaruh Pemupukan Kalium Terhadap Perkembangan Populasi Kutu Daun (Aphis Glycines. M) Dan Hasil Kedelai. Fakultas Pertanian, Universitas Malikussaleh. Vol. 9 . $83-92$ hal. 
Maimunah, S. 2003. Pengaruh Variasi Dosis Ragi dan Lama Fermentasi Terhadap Kadar Glukosa Dan Kadar Alkohol Pada Tape Ketan Hitam. Malang : FMIPA Jurusan Bilogi Universitas Islam Negeri Malang.

Odih, S. 2014. Pengaruh pemupukan kalium terhadap perkembangan populasi hama tungau jingga (Brevipalpus phoenicis Geijskes) pada tanaman teh (Camellia sinensis (L.) O. Kuntze). Jurnal Penelitian Teh dan Kina. Vol 17(1).Hal 39-46.

Schmitt, P. P. 1985. Preliminary and Advanced Evaluation of Nematicides. in : Sasser, J. N. and C. C. Carter (Eds). An Advanced Treatise on Meloidogyne. Vol. I. Biology and Control North Carolina State Ubiv. Graphics. Raleigh, North Caroline. pp. 241-246.

Sigit Wijayanto, Dewi Ratna Nurhayati, Efrain Patola. 2019. Kajian dosis pupuk kandang ayam dan frekwensi penyiraman terhadap bibit sengon (Paraserianthes falcataria (L) Nielson). Innofarm Jurnal Inovasi pertanian Vol 21 (2), Oktober 2019 ISSN (Print) : 1693-0738.

Wasis, S. dan R. Heru,P. 2013. Interaksi nitrogen dengan insidensi penyakit tungro dan pengendaliannya secara terpadu pada tanaman padi. Iptek Tanaman Pangan. Vol 8. No 2. 8089 hal. 